УДК 316.77:001.12/.18; 070:001.12/.18

DOI 10.18413/2712-7451-2020-39-1-15-24

\title{
РЕТРОСПЕКТИВА РАЗВИТИЯ ПОДТЕКСТА В РОССИИ
}

\section{RETROSPECTIVE OF SUBTEXT DEVELOPMENT IN RUSSIA}

\author{
А.С. Литовская \\ A.S. Litovskaya \\ Воронежский государственный университет, \\ Россия, 394018, г. Воронеж, Университетская площадь, 1 \\ Voronezh State University, \\ 1 University Square, Voronezh, 394006, Russia \\ E-mail: ann.litovskaya93@mail.ru
}

\begin{abstract}
Аннотация
В трудах отечественных филологов мы можем встретить различные подходы к исследованию текста. Особая роль в подобных работах отводится подтексту. Однако до сих пор никто не предпринимал попытки проследить проявление подтекста в российском историческом контексте с точки зрения журналистки. Поэтому целью данного исследования является попытка рассмотрения различных проявлений подтекста с момента возникновения письменности на Руси и до современных телепрограмм. Начальный этап связан с развитием письменности на Руси. В это время имплицитные смыслы выражаются преимущественно с помощью риторических приемов. С развитием книгопечатания и появлением печатных газет происходит усиление цензуры и идейного надзора за СМИ. В этот момент подтекст вновь трансформируется, беря на вооружение олицетворение и юмор. С появлением на страницах газет иллюстраций в виде картинок, появляется карикатура - мощное средство передачи подтекста. Дальнейшее развитие подтекста в нашей стране было обусловлено текущей политической ситуацией. $\mathrm{C}$ развитием и распространением телевидения подтекст начинает проявлять себя как с помощью вербальных, так и с помощью невербальных средств - мимики, жестов, интонирования. В современной сетевой среде он становится одним из ключевых факторов формирования комьюнити, своеобразным средством активации соучастия аудитории.
\end{abstract}

\begin{abstract}
In the works of Russian philologists, we can meet various approaches to the study of the text. A special role in such works is assigned to the subtext. However, so far no one has attempted to trace the manifestation of subtext in the Russian historical context from the point of view of a journalist. Therefore, the purpose of this study is an attempt to consider various manifestations of the subtext from the moment of writing in Russia to modern television programs. Having analyzed the theoretical and empirical material, we came to the conclusion that the subtext in its development went through several stages. The initial stage is associated with the development of writing in Russia. At this time, implicit meanings are expressed primarily through rhetorical devices. With the development of printing and the advent of the first printed newspapers, censorship and ideological oversight of the media has intensified. At this moment, the subtext is again transformed, taking on the arsenal of personification and humor. With the appearance of illustrations in the form of pictures on the pages of newspapers, a caricature appears - a powerful means of conveying subtext. Further development of the subtext in our country was due to the current political situation. For example, during the formation of Soviet power and World War II, the subtext was the most powerful tool for political propaganda. With the development and distribution of television, the subtext begins to manifest itself both through verbal and nonverbal means - facial expressions, gestures, intonation. In the modern network environment, it is becoming one of the key factors in the formation of the community, a kind of means of activating audience complicity.
\end{abstract}

Ключевые слова: подтекст, история, литературные жанры, цензура.

Key words: subtext, history, literary genres, censorship. 


\section{Введение}

История развития подтекста неразрывно связана с развитием публицистики и журналистики. В России авторы начинают прибегать к выражению имплицитных смыслов в тексте для того, чтобы избежать цензурных нападок и преследований. В разное время, в зависимости от внешней и внутренней политики страны, её социально-экономического устройства менялись и функции подтекста, и способы его выражения. К сожалению, в современной отечественной науке практически отсутствуют комплексные исследования, иллюстрирующие проявления подтекста именно в СМИ. Большинство работ, посвященных исследованию скрытых смыслов, разворачивается вокруг анализа художественнопублицистических текстов, существующих теорий текста или коммуникативных ситуаций на иностранных языках. Например, известны в данной области работы И.В. Арнольд [1974], И.А. Стернина [1979], И.Р. Гальперина [2005], Л.Г. Кайды [2010], Е.И. Лелис [2013], и ряда других исследователей, чьи научные идеи послужили отправной точкой в нашем исследовании. Вместе с тем мы не обнаружили работ, которые рассматривали бы подтекст в ретроспективе как в его печатных формах, так и в аудиовизуальных произведениях. Наше исследование представляет собой попытку компенсировать этот пробел.

Основной задачей данного исследования станет выявление ключевых вех в развитии подтекста, а также способов его проявления. Эмпирическим материалом послужат русскоязычные медиатексты в их печатной и аудиовизуальной форме, а ключевыми методами исследования станут текстологический, историко-функциональный и сравнительнотипологический анализ доступных нам документов.

\section{Основная часть}

Корни развития подтекста уходят в древнерусскую литературу, огромное влияние на развитие которой сыграло крещение Руси. В этот же период постепенно начинает формироваться система литературных жанров. Их можно разделить на «мирские» и «духовные» [Кусков, 2003, с. 5]. Что касается подтекста в это время, то он проявляется с помощью схожих средств, но выполняет разные функции. В «мирской» части впервые имплицитные смыслы начинают проявляться с помощью элементов политической манипуляции, которые необходимы для создания определенного образа в памяти потомков. В «духовной» части подтекст выражается с помощью иносказаний, олицетворений, а также аллегорий, метафор и, конечно, символизма. Вспомним, например, христианские притчи «О сеятеле», «О плевелах», «О злых виноградарях» и другие, а также творения латинских раннехристианских авторов [Прутцков, 2012, с. 248].

Анализ же светских памятников древнерусской литературы показывает, что авторы стремились не только показать аудитории достойный пример жизни, но и воздействовать на нее с помощью подтекста. В качестве примера рассмотрим «Поучение Владимира Мономаха». В данном случае подтекст «скрыт» в назидательном характере повествования и передан с помощью цитат из Священного Писания, а также аллегорий и сравнений: «Когда он упадет, то не разобьется, ибо Господь поддерживает руку его. Молод был и состарился, и не видел праведника покинутым, ни потомков его просящими хлеба» ${ }^{1}$. Как мы видим, стилистика данного отрывка напоминаем нам строчки из писания. В данном случае подтекст выражен с помощью аллегорий «просящий хлеба»- терпящий нужду в чемто; «Господь поддерживает руку его» - Бог помогает, удача сопутствует и т.д. С помощью подтекста Владимир Мономах дает необходимые знания о жизни потомкам.

Следующим важным этапом в развитии подтекста можно считать начало XVIII века. В России это время ознаменовано появлением частных периодических изданий, которые с помощью иронии и сарказма пытались привлечь внимание соотечествен-

${ }^{1}$ Поучение Владимира Мономаха [Электронный ресурc]. URL:https://azbyka.ru/otechnik /Vladimir_Monomah/pouchenie/ (дата обращения 17.11.2019). 
ников к экономическим, политическим и культурным проблемам того времени. К примеру, А.Н. Сумароков в журнале «Трудолюбивая пчела» ${ }^{1}$ активно использует иносказание и иронию. Так, в тексте «Разговоры мертвых» он с помощью иносказаний обличает множество человеческих пороков: скупость, тщеславие, расточительство. Подтекст здесь актуализируется словосочетаниями «титла привязывается», «пустая титла», «фортуна слепа», которые намекают на ситуацию неравенства.

Следующим этапом развития подтекста становится создание карикатур, яркие примеры которых мы находим в начавшем выходить в 1859 году сатирическом еженедельнике «Искра» [Бережной, 2004]. Например, на одной из картинок был изображен господин, который нес большую связку книг. Встречный прохожий спрашивает его: «Донесете ли вы это?» «Помилуйте, - отвечает тот, - и не это доносил» [Лебедева, 1959, с.16]. Подтекст здесь реализуется не только с помощью картинки, но и через использование многозначности слова «донести».

Не менее важной вехой в развитии подтекста, стали произведения И.А. Крылова, который использовал весь его иронический потенциал. Причем в его произведениях впервые был использован подтекст сразу на двух уровнях - семантическом и композиционном. Вспомним, например, его книгу очерков и фельетонов «Почта духов» (1789 г.) $)^{2}$. Подтекст «первого уровня» формируется с помощью олицетворения. Повествование ведется не от лица рассказчика, а как бы от лица «водяных, воздушных и подземных духов». Подтекст «второго уровня» реализуется с помощью некоторых риторических приемов. Например, с помощью противопоставления Крылов показывает свое отношение к «модным щеголям», бездумно копирующим западную моду. Иван Андреевич продолжает здесь линию Фонвизина и Новикова, считая, что нам не стоит копировать западный уклад жизни, каким бы привлекательным он не был. На наш взгляд, «ветер» в данном контексте обозначает модные веяния или тенденции, которые, к сожалению, в «грязи» (то есть в наших, российских реалиях) не приживаются. Также подтекст реализуется через перечисление и гиперболу: автор ставит в один ряд с нечистью «пьяных подъячих» и «злых вельмож», то есть, по сути чиновников, намекает на то, что социальное расслоение в стране существует в катастрофических масштабах и предлагает «протереть глаза» - то есть смотреть на суть проблемы.

В XX веке полемика в СМИ лишь усилилась [Махонина, 2002; Есин, 2003]. Связано это было, прежде всего, с изменениями в государственном строе. С точки зрения развития подтекста заметную роль сыграл в то время Влас Дорошевич с его фельетонами. В его текстах активно используется прием «типизирования» персонажей. Например, вспомним текст «Поэтесса. Рассказ одного критика». С помощью описания лишь некоторых характерных черт предполагаемого действующего лица, Влас Михайлович добивается поистине карикатурного сходства с реальными людьми, встретиться с которыми может любой из нас и по сей день. Причем автор абстрагируется от поступков своих героев, не осуждая и не одобряя их, он просто описывает ситуацию, активно используя подтекст. Итак, ситуация, описанная в «Поэтессе», следующая: некий «г-н Пулеметов» (говорящая фамилия) приходит в газету к условному «литературному критику», кладет ему на стол «книжку г-жи Пулеметовой. В ней 764 стихотворения» ${ }^{3}$ с немедленным требованием опубликовать в ближайшем номере газеты отзыв, причем непременно положительнохвалебного содержания. И дальше по большому счету можно было бы ничего не писать, просто отказав Пулеметову. Но ведь задача Дорошевича в другом: высмеять нравы, показав всех и никого конкретно. Поэтому в тексте появляется набор аргументов, которыми

${ }^{1}$ Сумароков А. Н. Разговоры мертвых [Электронный ресурс]. URL: http://sumarokov.litinfo.ru/sumarokov/publicistika/public-23.htm (дата обращения 17.11.2019).

${ }^{2}$ Крылов И.А. Почта духов [Электронный ресурc]. URL: https://rvb.ru/18vek/krylov/01text /vol1/01prose/001.htm (дата обращения 17.11.2019).

3 Дорошевич В. М. Поэтесса [Электронный ресурс]. URL: https://e-libra.ru/read/82540poetessa-rasskaz-odnogo-kritika.html (дата обращения 17.11.2019). 
Пулеметов пытается уговорить редактора написать отзыв. Первый аргумент - лесть («Mbl ваши ужасные поклонники. В особенности жена! Прямо влюблена. Утром, знаете, как только проснется, еще в постели, первым долгом: «Где он?». Это про вас, а не про чтонибудь другое» ${ }^{1}$ - фраза направлена на то, чтобы подчеркнуть «значимость» литературного критика в жизни семьи - жена влюблена, только о вас и говорит; вторым аргументом явилась фраза «Я вам скажу, как родному отиу!» ${ }^{2}$ (что должно расположить к себе критика, так как родным людям доверяют все самое ценное, сокровенное, что не расскажут другому); наконец, самый «сильный» аргумент Пулеметов произносит в конце, говоря о том, что «моя жена беременна и выпустила стихи!». Казалось бы, достаточно просто поздравить будущего отца и на этом разойтись, но ведь здесь Пулеметов намекает на известный стереотип: у беременных женщин часто меняется настроение. В качестве аргумента Пулеметов использует шантаж, манипулируя словами врача о том, что жене никак нельзя волноваться: "Доктор говорит: "Малейшее волнение...". А она выпустила стихи. Первый неблагоприятный отзыв - и она сбросит! - Как сбросит? - Младениа сбросит! Не донесет и сбросит! Ради бога! Когда будете писать, имейте это в виду! Она сбросит!» ${ }^{3}$. То есть чистой манипуляцией, шантажом, игрой со стереотипами Пулеметов фактически заставляет критика написать отзыв. Дорошевич, описывая эту ситуацию, дает понять читателю, что такие «авторы» попадаются очень часто, но не понимают главного - важно не количество написанного, а его качество.

После падения царизма власть взяли в руки большевики. Подтекст в то время обогатился за счет политической манипуляции и пропаганды. Писателям и журналистам оставалось либо эмигрировать, либо учитывать интересы и вкусы правящей партии [Исключить всякие упоминания..., 1995]. Но иногда и в столь непростой политической ситуации находились те, кто пытался с помощью подтекста донести до своего читателя определенные мысли, которые наверняка не понравились бы советской цензуре. Примером могут служить тексты Л. Сосновского («Тяжелые дни Волховстроя», «Лед пошел», «Смагин» и др.), которые, с одной стороны, воспевали «человека труда», не желающего сил и времени для общественной пользы, а с другой стороны - показывали всю неприглядную сторону советской бюрократии [Кузнецов, 2003].

Рассмотрим подробнее текст «Смагин». В нем Сосновский пользуется намеком, чтобы передать имплицитный смысл: «Возьмите городскую промышленность. Вот я, Смагин, чумазый рабочий, изобрел топку для нефтяных паровозов. Моя топка экономнее многих других. Её испьтывали специиалисты и признали, что она хороша, дает столькото процентов экономии. А ходу ей нет. Только на одной дороге она пошла. А почему? Надо издать инструкцию для всех дорог» ${ }^{4}$. Подтекст выражен фразой «а ходу нет», нет широкого применения этой идеи. Парадокс: мысль хорошая, все работает, а дальше в широкое производство не идет. Но автор не просто с горечью констатирует этот факт. Он идет дальше, объясняя читателю с помощью подтекста, почему так происходит: «Вот уже полтора года хожу я по большевикам, пороги обвиваю. Прошу заняться инструкциями. Ребята надо мной смеются. Дурак ты, - говорят, - Смагин. Ну, что ты подметки треплешь. Tbl бы часа два поработал в мастерской, починил велосипед, керосинку, швейную машину - вот тебе на пуд хлеба хватит. А ты инструкции у большевиков ищешь. Не будет никаких инструкиий для слесарей и мыловаров. Брось ты свои глупости» ${ }^{5}$. Подтекст выражен через отрицание («не будет никаких инструкций») и сравнение («для слесарей и

1 Дорошевич В. М. Поэтесса [Электронный ресурс]. URL: https://e-libra.ru/read/82540poetessa-rasskaz-odnogo-kritika.html (дата обращения 17.11.2019).

${ }^{2}$ Там же.

${ }^{3}$ Там же.

${ }^{4}$ Сосновский Л. С. Смагин [Электронный ресурc] URL: http://az.lib.ru/s/sosnowskij_1_s /text_1921_smagin.shtml (дата обращения 17.11.2019).

${ }^{5}$ Там же. 
мыловаров»). Это означает, что нет инструкций для людей рабочих профессий, которым, по идее, они нужны больше всех, чтобы наладить качественное производство.

Отдельного внимания заслуживает история подтекста периода Второй мировой войны. Многочисленные очерки, фронтовые заметки, плакаты и лозунги - везде можно было встретить пропаганду, выраженную через «двойные» смыслы [Brooks, J. 1985]. Ocoбенно сильно подтекст обогатился за счет плакатов и листовок, которые часто использовали как союзники нашей страны, так и противники.

На протяжении Великой Отечественной войны агитация и пропаганда играли значительную роль [Kenez, P. 1985]. Подтекст в этом процессе был первейшим способом воздействия на массы. Предлагаем обратить внимание на творчество Кукрыниксов коллектив художников-графиков и живописцев. Интересно выражение подтекста через использование «зоообразов». Данный прием был весьма частотным. Так, Кукрыниксы стремились подчеркнуть бесчеловечный характер фашистов. Рассмотрим конкретные примеры. В карикатуре, созданной художниками в 1941 году, мы видим Адольфа Гитлеpa, обгладывающего кость, и его союзников в образах собак у «хозяйского стола», готовых в любой момент эту кость проглотить - Бенито Муссолини, Миклоша Хорти, Йозефа Тисо, Йона Антонеску ${ }^{1}$. Все эти люди слушались команды немецкого вождя, как преданные собаки, не задумываясь о последствиях. Появление кости в данном контексте тоже кажется нам неслучайным - это намек на жертв войны и концлагерей, погибших от рук вышеназванных лиц.

Наконец, становление отечественного телевидения прошло в своем развитии три этапа. Обратимся к периодизации, предложенной В. Кацевым в книге «История отечественной журналистики»: первый этап (1907-1957 гг.), второй этап (1957-1970 гг.), третий этап (1970-1985) [Кацев, 2004]. Конечно, данная периодизация весьма условна, но все же позволяет вычленить некоторые вехи в истории развития подтекста на телеэкране. Остановим свое внимание на втором и третьем этапе как наиболее продуктивном с точки зрения создания готового информационного продукта. Как подтекст выражал себя в условиях тотальной цензуры? Вообще, возможен ли он был?

Давайте проанализируем некоторые популярные программы с точки зрения выражения в них имплицитного смысла. Из истории мы знаем, что в Советском Союзе едва ли не на всех этапах его существования царила жесткая цензура [Gorham, 2003]. Однако даже на советском телевидении мы можем найти примеры, когда журналистам удавалось обходить жесткие цензурные рамки именно с помощью подтекста. Например, при анализе выпусков музыкально-юмористических передач (таких как «Кабачок "13 стульев", «Вокруг смеха», «Утренняя почта»), которые выходили в период с 1966 по 1991 годы, мы обратили внимание на то, что во всех трех вышеназванных программах практически отсутствуют какие-либо остросоциальные и политические темы. Казалось бы, где ещё можно в завуалированной, «легкой» форме сказать всё, что думаешь о советской власти и ситуации в стране? Но в этих программах присутствуют довольно безобидные шутки только о какихто общих темах: о семье, погоде, самих ведущих и так далее. На современном молодежном сленге такие шутки называются «подколами». Вот, например, в одном из выпусков «Кабачка» актеры произносят такие реплики: «-Bbl что, с Луны свалились? - Нет, я из дома» ${ }^{2}$ и так далее.

Гитлер и кость. URL: http://kotindom.ru/art/11-kukryniksy-voennye-plakatyvelikoyotechestvennoy-voyny.html (дата обращения 17.11.2019).

2 Кабачок 13 стульев. URL: https://yandex.ru/video/preview?filmId=1142660772014622217 \&text=кабачок\%2013\%20стульев\%20вы\%20с\%20луны\%20свалились\&from=tabbar\&parentreqid=1574019933989543849895127817416282300129-man1-3576 (дата обращения 17.11.2019). 
Совершенно иначе складывалась ситуация в новостных и аналитических передачах [Remington, 1981]. Например, выпуски программы «Международная панорама», выходившей с 1969 по 1991 гг. на ЦТ Гостелерадио СССР. Здесь уже подтекст выражен более ярко по ряду причин. Во-первых, программа носит политический характер. Во-вторых, программа строится на контрасте социалистического СССР и остального мира, где с помощью создания определенного подтекста авторам удается умело манипулировать общественным мнением. Примером может служить выпуск под названием «Информационное невежество американцев». Программа начинается с того, что ведущий Леонид Липовецкий пытается опровергнуть слова знаменитой американской журналистки Барбары Уолтерс о том, что американцы - самая информированная нация: «B Нью-Йорке, например, передачи идут уже круглье сутки, а по вечерам работают не менее 20 каналов» ${ }^{1}$. Затем ведущий задает студентам колледжа ряд общих вопросов, связанных с СССР, и американские подростки с трудом могут сразу правильно ответить. «Так в действительности обстоят дела с "информированностью" американской публики» ${ }^{2},-$ ехидно произносит журналист за кадром. И сами вопросы, и тон ведущего, и подводка к синхронам американских студентов - всё говорит нам о глубоком предубеждении журналиста в отношении опрошенных им респондентов. Впрочем, почти каждый выпуск программы посвящен неприкрытой пропаганде хорошей жизни в Советском Союзе. Авторы программы с помощью разных манипуляций с экранным изображением и текстом создают определенную картину действительности [Rogers, 1971].

Исследуя современное состояние подтекста на российском телевидении, можно сделать вывод о том, что он присутствует в различных телепередачах, а характер его представленности зависит, прежде всего, от жанра конкретной телепрограммы и имиджа телеведущего [Шестерина, 2019]. Последнее отличает его от подтекста печатных медиа, поскольку имидж включает существенный спектр невербальных средств. Следовательно, и подтекст в телепередачах, как правило, выражается с помощью сочетания вербальных и невербальных компонентов. Подобная «двойственность» обусловлена самой природой аудиовизуальных СМИ. Как отмечает доктор филологических наук, профессор А.М. Шестерина, аудиовизуальную информацию можно разделить на две большие категории - аудиальные и визуальные субмодальности [Шестерина, 2011, с. 86]. Аудиальные позволяют воспринимать слова и звуки, громкость, тон (резкий или мягкий), длительность, непрерывность или прерывность, темп (быстрее или медленнее обычного). К визуальным относят цветность изображения, местоположение в кадре, яркость и контрастность, подвижность, размер. Что касается вербальных аудиальных форм выражения подтекста, то, как отмечает исследователь Н.С. Валгина, «в системе категорий лингвистических фрагментов текст есть функционально, содержательно и структурно завершенное речевое единство, скрепленное авторской модальностью. Любой текст - разнофункциональный и разномодальный - это прежде всего совокупность предложений-высказываний, которые, группируясь на основе смысловых и структурных (межфразовых) связей, объединяются в единицы текста - межфразовые единства, компоненты или фрагменты текста, наконец, целое речевое произведение» [Валгина, 2004 с. 27].

Множество разнообразных форм и функций подтекста мы нашли, проанализировав ток-шоу («Время покажет», «60 минут»), юмористические передачи («Вечерний Ургант», «Comedy Club» и др.), трэвел-шоу («Орел и Решка») и различные художественные фильмы и сериалы. Меньше всего подтекста мы обнаружили в информационных («Время», «Итоги» и др.) и познавательных («Открытая наука», «Игра в бисер» и др.). Например, большое значение в психологическом проявлении подтекста имеет несовпадение «картинки» и звука. Этим способом выражения подтекста часто пользуются в новостных выпус-

${ }^{1}$ Международная панорама. URL: https://www.youtube.com/watch?v=JkJYco0Bmzo (дата обращения 17.11.2019).

${ }^{2}$ Там же. 
ках. В одном из эфиров итогового выпуска телепрограммы «Вести» ${ }^{1}$ во время обсуждения цен на российский газ для турецких коллег Владимир Путин говорит о том, что цены на российский газ устанавливает не Газпром, а мировое сообщество. В этот же момент камера как бы невзначай выхватывает сидящего в зале турецкого дипломата, который демонстративно смеется во время этих слов.

На вербальном уровне подтекст может быть выражен с помощью иносказаний, актуализации энциклопедических сведений, актуализации стереотипов, использования в одной коммуникативной ситуации разных значений одного и того же слова и т.д. [Стернин, 2011]. Особенно эти приемы частотны в юмористических шоу и молодежных телепрограммах. Например, в одном из выпусков «Вечернего Урганта» ведущий говорит: «Пример Лолиты показывает: не все Дуремары приносят пиявки, которые действительно помогают» ${ }^{2}$. Алчные врачи не помогают. Дуремар - известный персонаж из сказки Алексея Толстого «Буратино». Это шарлатан, алчный человек, который утверждал, что пиявки могут вылечить от всех болезней, и старался на них обогатиться. В данном случае ведущий намекает на целую сеть неквалифицированных врачей, разных шарлатанов, которые вместо адекватного лечения предложат «пиявки», то есть какую-то ерунду. Скрытый смысл актуализируется фразой «не все Дуремары приносят пиявки, которые действительно помогают», в которой слово «Дуремары» выступает символическим обозначением врачей-шарлатанов. Или, например, рассмотрим реалити-шоу «Орел и решка». В нем ведущие активно используют первичный уровень подтекста - семантический. С его помощью ведущие и достигают необходимого «комического» эффекта своих сообщений [Пропп, 1976].

Рассмотрим приемы, с помощью которых ведущие актуализируют подтекст, в выпуске «Лондон. Перезагрузка. Ru $»^{3}$.

Девушка одета в светлые джинсы и футболку с глубоким декольте.

- Настенька, ты времени даром не теряешь. Абрамович развелся, а ты тут как тут со своим декольте.

- Антон, ну мне же нужно как-то устраивать свое будущее.

В данном случае подтекст реализуется с помощью намека на бурную личную жизнь российского бизнесмена Романа Абрамовича, который, как известно, имеет свою недвижимость в Лондоне. Сарказм актуализируется намеком на путь в «хорошую жизнь», то есть брак с успешным мужчиной, благодаря чему можно жить в одном из самых дорогих городов мира ни в чем не нуждаясь.

\section{Заключение}

В нашем исследовании мы впервые в отечественной науке проанализировали основные вехи становления и развития довольно сложного, но крайне важного в медиасфере явления - подтекста, выявили ключевые этапы его становления, наиболее частые приемы выражения и создаваемые эффекты.

Мы рассмотрели основные вехи развития подтекста в России в ретроспективе. Конечно, мы не заострили внимание на многих знаковых текстах русской литературы, лишь попытались обобщить наиболее яркие тексты классиков русской литературы и журналистики, чтобы понять, как развивался подтекст от первых рукописных памятников до теле-

17.11.2019).

1 Вести. URL: https://www.vesti.ru/videos/show/vid/817437/cid/1/ (дата обращения

2 Вечерний Ургант. URL: https://www.1tv.ru/shows/vecherniy-urgant/vypuski/lolita-i-motvecherniy-urgant-1107-vypusk-ot-05-04-2019 (дата обращения 17.11.2019).

3 Орел и Решка. Лондон. URL: https://yandex.ru/search/?lr=193\&clid=9403\&oprnd $=5133993075 \&$ text $=$ opëл\%20и\%20решка\%20лондон\%20перезагрузка\#/videowiz?filmId=1743560376 6954557453 (дата обращения 17.1.2019). 
видения. Нам удалось установить, что вначале подтекстом пользовались иносказательно с помощью риторических приемов. Затем, с развитием книгопечатания и выпуском первых частных газет в России, подтекст стал проявлять себя уже через олицетворение, сравнение, иронию и сатиру.

Примерно в это же время на службу журналистам и писателям приходят попытки создать определенный образ с помощью невербальной коммуникации. Так постепенно слово дополняет картинка - карикатура, шарж. Приход к власти большевиков и установление тотальной цензуры привел к тому, что авторы начали возвращаться к риторическим приемам, активно используя олицетворение для передачи имплицитного смысла. Период Великой Отечественной войны вновь возвращает нас к силе визуального искусства, особенно когда дело касается военных плакатов. Здесь подтекст мощно заявляет о себе как об инструменте политической манипуляции и пропаганды.

Наконец, на советском телевидении подтекст также проходит несколько этапов в своем становлении и развитии - от полного неприятия до использования в программах определенных жанров. Современное состояние подтекста свидетельствует о том, что он часто используется на современном отечественном телевидении. Правда, его существование обусловлено конкретным форматом программы, жанром, манерой поведения телеведущих. Наиболее часто подтекст проявляется в юмористических и реалити-шоу, меньше всего имплицитных смыслов в новостных выпусках и научно-познавательных программах.

В целом, можно констатировать тот факт, что в разное время, в зависимости от внешней и внутренней политики нашей страны, её социально-экономического устройства менялись и функции подтекста, и способы его выражения.

\section{Список литературы}

1. Арнольд И.В. 1974. Стилистика декодирования. Л., ЛГПИ: 76 с.

2. Бережной А.Ф. 2004. Сатирическая журналистика. СПб., Лаборатория оперативной печати ф-та журналистики СПбГУ, 39 с.

3. Введение в мировую журналистику. От Античности до конца XVIII века. 2007. Сост. Г.В. Прутцков. М., Аспект Пресс, 427 с.

4. Валгина Н.С. 2004. Теория текста. М., Логос, 280 с.

5. Гальперин И.Р. 2005. Текст как объект лингвистического исследования. М., Едиториал УРCC, $137 \mathrm{c}$.

6. Есин Б.И. 2003. История русской журналистики XIX века. М., Аспект Пресс, 288 с.

7. Исключить всякие упоминания...: Очерки истории советской цензуры. 1995. Сост. Т.М. Горячева. Мн., «Старый Свет-принт», 334 с.

8. Кайда Л. Г. 2010. Композиционная поэтика текста. М., Флинта, Наука, 400 с.

9. Кацев И.Г. 2004. История российского телевидения, 1907-2000. М., РГГУ, 255 с.

10. Кузнецов И.В. 2003. История отечественной журналистики (1917-2000). М., Флинта, Наука, 640 с.

11. Кусков В.В. 2003. История древнерусской литературы. М., Высшая школа, 336 с.

12. Лебедева Г.М. 1959. Сатирический журнал «Искра» - орган передовой демократической печати 1859-1873. М., Советская Россия, 84 с.

13. Лелис Е.И. 2013. Подтекст как лингвоэстетическая категория в прозе А. П. Чехова. Ижевск, Удмуртский университет, 424 с.

14. Махонина С.Я. 2002. История русской журналистики начала XX века. М., Наука, 240 с.

15. Особенности функционирования современных аудиовизуальных медиа. 2018. Под общ. ред. А.М. Шестериной. Воронеж, Кварта, 254 с.

16. Пропп В.Я. 1976. Проблемы комизма и смеха. М., Искусство, 183 с.

17. Стернин И. А. 1979. Проблемы анализа структур значения слова. Воронеж: Изд-во Воронежского госуниверситета, $122 \mathrm{c.}$ 
18. Brooks J. 1985. When Russia Learned to Read: Literacy and Popular Literature, 1861-1917 (Princeton UP, 1985). Available at: https://archive.org/details/whenrussialearne00broo (accessed: 17.11.2019).

19. Remington T. The mass media and public communication in the USSR. Available at: https://www.journals.uchicago.edu/doi/10.2307/2130638 (accessed: 17.11.2019).

20. Gorham M.S. 2003. Speaking in Soviet Tongues: Language Culture and the Politics of Voice in Revolutionary Russia. Available at: https://archive.org/details/speakinginsoviet0000gorh (accessed: 17.11.2019).

21. Kenez P. 1985. The Birth of the Propaganda State: Soviet Methods of Mass Mobilization, 1917-1929 (Cambridge UP, 1985). Available at: https://archive.org/details /TheBirthOfThePropagandaStateSovietMethodsOfMassMobilization19171929/page/n2 (accessed: 17.11.2019).

22. Rogers R. 1971. The Soviet mass media in the sixties: Patterns of access and consumption. Journal of Broadcasting \& Electronic Media. Available at: https://www.cambridge.org/core /journals/slavic-review/article/finding-a-home-for-television-in-the-ussr19501970/1ABF26C5E5DC 747BA7E5E3116223ED82 (accessed: 17.11.2019).

\section{References}

1. Arnold IV. 1974. The style of decoding. L., Leningrad State Pedagogical Institute: 76 p.

2. Berezhnoy A.F. 2004. Satiricheskaja zhurnalistika [Satirical journalism]. SPb., Operational press laboratory of the journalism faculty of St. Petersburg State University, $39 \mathrm{p}$.

3. Vvedenie v mirovuju zhurnalistiku. Ot Antichnosti do konca XVIII veka [Introduction to world journalism. From Antiquity to the End of the 18th Century]. 2007. Comp. G.V. Prutskov. M., Aspect Press, $427 \mathrm{p}$.

4. Valgina N.S. 2004. Teorija teksta [Text Theory]. M., Logos, 280 p.

5. Halperin I.R. 2005. Text as an object of linguistic research. M., URSS editorial, 137 p.

6. Yesin B.I. 2003. Istorija russkoj zhurnalistiki XIX veka [The history of Russian journalism of the 19th century]. M., Aspect Press, 288 p.

7. Iskljuchit' vsjakie upominanija...: Ocherki istorii sovetskoj cenzury [To exclude all references ...: Essays on the history of Soviet censorship]. 1995. Comp. T.M. Goryacheva. Mn., «Staryj Svet-print», $334 \mathrm{p}$.

8. Kaida L.G. 2010. Compositional poetics of the text. .M., Flint: Science, 400 p.

9. Katsev I.G. 2004. Istorija rossijskogo televidenija, 1907-2000 [History of Russian television, 1907-2000]. M., RGGU, 255 p.

10.Kuznetsov I.V. 2003. Istoriya otechestvennoy zhurnalistiki (1917-2000) [History of Russian journalism (1917-2000)]. M., Flinta: Nauka, 640 p.

11.Kuskov V.V. 2003. Istoriya drevnerusskoy literatury [History of Old Russian Literature]. M.: Vysshaya shkola, $336 \mathrm{p}$.

12.Lebedeva G.M. 1959. Satiricheskiy zhurnal «Iskra» - organ peredovoy demokraticheskoy pechati 1859-1873 [The satirical magazine Iskra. The body of the advanced democratic press 18591873]. M., Sovetskaya Rossiya, 84 p.

13.Lelis E.I. Lelis E.I. 2013. Subtext as a linguo-aesthetic category in A.P. Chekhov's prose. Izhevsk: Udmurt University, 424 p.

14.Makhonina S.Ya. 2002. Istoriya russkoy zhurnalistiki nachala XX veka [History of Russian journalism at the beginning of the 20th century]. M., Nauka, $240 \mathrm{p}$.

15.Features of the functioning of modern audiovisual media. 2018. Ed. A.M. Shesterina. Voronezh: Quart, 254 p.

16.Propp V.Ya. 1976. Problemy komizma i smekha [Problems of comism and laughter]. M., Iskusstvo, $183 \mathrm{p}$.

17.Sternin I. A. 1979. Problems of analyzing the structure of the word meaning. Voronezh: publishing house of Voronezh state University, $122 \mathrm{p}$. 
18.Brooks J. 1985. When Russia Learned to Read: Literacy and Popular Literature, 1861-1917 (Princeton UP, 1985). Available at: https://archive.org/details/whenrussialearne00broo (accessed: 17.11.2019).

19. Remington T. The mass media and public communication in the USSR. Available at: https://www.journals.uchicago.edu/doi/10.2307/2130638 (accessed: 17.11.2019).

20.Gorham M.S. 2003. Speaking in Soviet Tongues: Language Culture and the Politics of Voice in Revolutionary Russia. Available at: https://archive.org/details/speakinginsoviet0000gorh (accessed: 17.11.2019).

21.Kenez P. 1985. The Birth of the Propaganda State: Soviet Methods of Mass Mobilization, 1917-1929 (Cambridge UP, 1985). Available at: https://archive.org/details /TheBirthOfThePropagandaStateSovietMethodsOfMassMobilization19171929/page/n2 (accessed: 17.11.2019).

22.Rogers R. 1971. The Soviet mass media in the sixties: Patterns of access and consumption. Journal of Broadcasting \& Electronic Media. Available at: https://www.cambridge.org/core /journals/slavic-review/article/finding-a-home-for-television-in-the-ussr19501970/1 ABF26C5E5DC 747BA7E5E3116223ED82 (accessed: 17.11.2019).

\section{Ссылка для цитирования статьи For citation}

Литовская А.С. 2020. Ретроспектива развития подтекста в России. Вопросы журналистики, педагогики, языкознания. 39 (1): 15-24. DOI 10.18413/2712-7451-2020-39-1-15-24

Litovskaya A.S. 2020. Retrospective of subtext development in Russia. Issues in Journalism, Education, Linguistics.. 39 (1): 15-24. (in Russian). DOI 10.18413/2712-7451-2020-39-1-15-24 